\title{
VOLTAGE CONTROLLED SEPIC CONVERTER FED INDUCTION MOTOR DRIVE
}

\author{
${ }^{1}$ Shital Bakal and ${ }^{2}$ Sanjay M. Shinde \\ ${ }^{2}$ Assistant Professor \\ Electrical Engineering Department \\ Government College of Engineering,Aurangabad,India \\ Email: $\left\{{ }^{1}\right.$ shital.baka193@gmail.com, ${ }^{2}$ smshinde.ee@geca.ac.in $\}$
}

\begin{abstract}
In current era hasty progression of power semiconductor devices is amplified extensive succession for applications i.e., industrial, along with several others. The harmonics deformation formed by converter has being too stern concern to consistent operation for system. And also, a customary technique with rectifier has unfavorable penalty with complementary losses. This paper explains investigation of SEPIC converter for enhancement in quality of power with PFC supplied to induction motor. The recommended scheme offered reduction for THD by using PI system through voltage follower scheme. A performance for designed converter is simulated at MATLAB, providing enhanced quality to power at AC supply.
\end{abstract}

Keywords- SEPIC, DCM, DBR, PWM

\section{Introduction}

Nowadays, a DC - DC converters are commonly used universally. These are engaged for power supplies, lightning, industrial applications. These are also applied as power converter to photovoltaic power systems, as suggested in [1]

Novel scheme with SEPIC is intended for DCM to supply of arc welding gives intrinsic PFC with diminish in losses of conduction and augmentation for efficiency provided THD at $5.36 \%[3][2]$

The authors has designed higher frequency converters to link output for bridge towards load for achieving high PF, and complex frequency isolation along with compacted size provided THD around $8.25 \%$ [2] [3]

In [4] authors explored performance of Solar Energy Transformation System proposed to sustain grid power and augmentation power quality by employing $\mathrm{H}$ bridge, multilevel, inverter and SIMO SEPIC Converter offers lower THD about $1.65 \%$.

Another author suggested a new scheme employing a multilevel inverter which is grid connected along with isolated SEPIC for Solar PV scheme concludes reduced switching devices with maximum voltage level and flexible power processing and regulation too.[5]

Another approach by some author [6] has been adopted ZVS and PFC using bridgeless converter operating in both DCM and CCM, provided improved power factor and efficiency.

DC-DC converters gives elevated efficiency, speedy dynamic response. These can also be used for voltage regulations and to produce $\mathrm{DC}$.

In paper, SEPIC is employed for analysis performance. Its topology is investigated and result analysis provided their aptness for augmentation in PF and decrements in THD leading to power quality improvement.

\section{Converter Study}

Fig. 1 reveals block illustration for preferred converter scheme consisting DBR, supplied with AC, converter, along with load furthermore control circuitry.

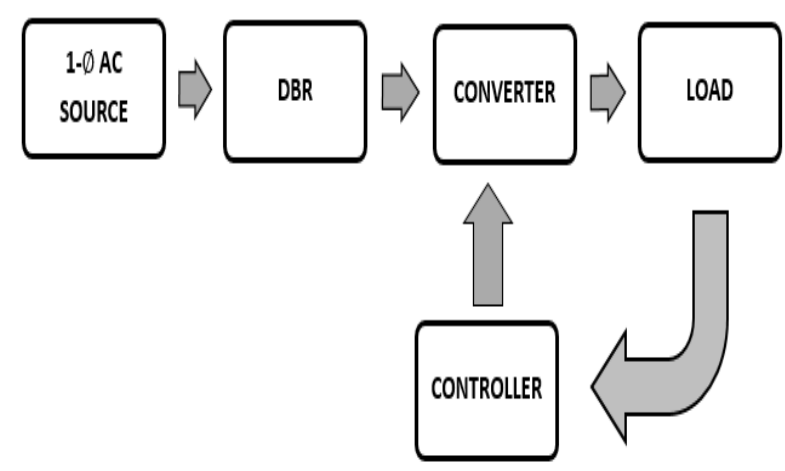

Fig.1. Block Diagram for Anticipated Converter Scheme

In topology an AC is supplied to DBR, that adapts AC into DC. which is fed to particular converter. With crucial control scheme PWM pulse are supplied to trigger switch of converter. There may be any converter like SEPIC, zeta etc.

\section{Proposed Scheme}

The proposed system used for Induction motor drive with SEPIC converter working for voltage follower approach depicted in Fig. 2.

Single phase DBR followed by SEPIC converter is commissioned for regulation of DC voltage along with enhancements of PF along with power quality across AC mains. Switch is functioned at particular switching frequency given effectual control with condensed component rating. MOSFET of appropriate rating has employed in converter for higher frequency operation however IGBTs are engaged at VSI for lower frequency function. 


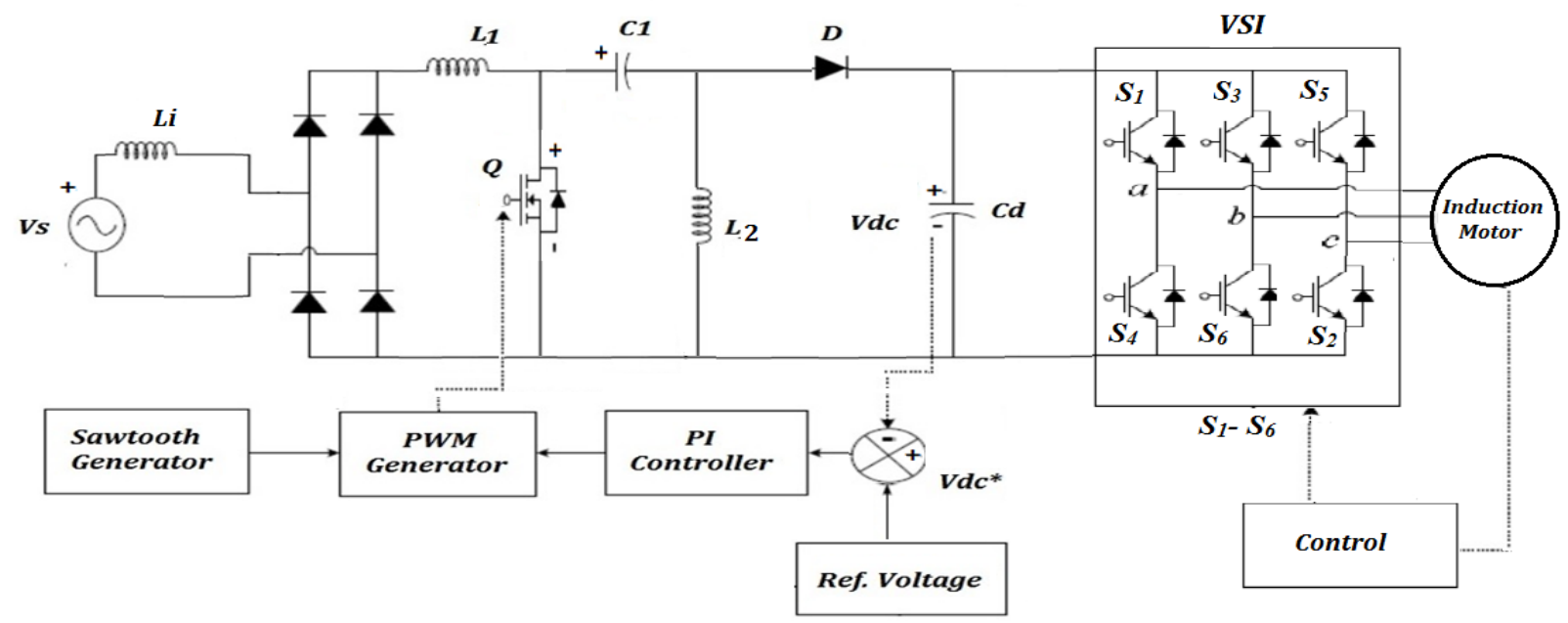

Fig. 2. Block Diagram for Proposed Scheme

The intended SEPIC converter is proposed to work at DCM, SEPIC converter retains voltage from DC link at fixed rate of reference.

DC link voltage $\mathrm{V}_{\mathrm{dc}}$ is equated by means of $\mathrm{V}_{\mathrm{dc}} *$ to produce error signals i.e., deviation of $\mathrm{V}_{\mathrm{dc}} *$ and $\mathrm{V}_{\mathrm{dc}}$ The voltage error is fed with PI controller. At last, controlled yield is liken with saw tooth wave that capitulate pulses of switching for appreciated converter.

\section{Proosed Converter}

The switching scheme for SEPIC converter represented by Fig3. It comprises of two coupled inductors, MOSFET switch working at privileged frequency, two capacitors and diode to freewheel.

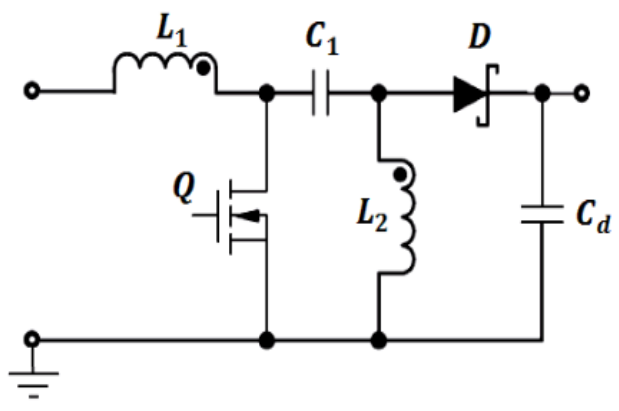

Fig. 3. SEPIC Converter

During steady state, voltage that across inductor becomes zero consequently magnitude of Capacitor voltage at $\mathrm{C}_{1}$ is $\mathrm{V}_{\mathrm{Cl}}=\mathrm{V}_{\mathrm{s}}$. It is having two modes of operation mode 1 and mode 2 according to operating condition of switch.

Through Mode 1, the diode is open, the L1 Inductor supplied by sources Vs i.e. while switch is disabled. C1. The output is maintained either by $\mathrm{C} 2$ condenser through L2 inductor. VL1 $=\mathrm{Vs}$ is the agitation in L1.

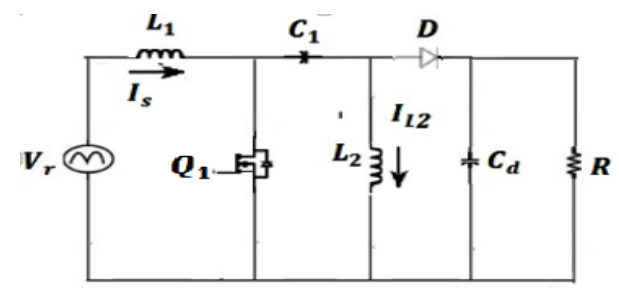

Fig. 4. Mode1

The diode is triggered while $\mathrm{L} 1$ provides $\mathrm{C} 1$ and $\mathrm{L} 2$ sends power to load when switch is opened. $\mathrm{L} 1$ is $\mathrm{VL1}=-\mathrm{Vo}$ voltage through L1.

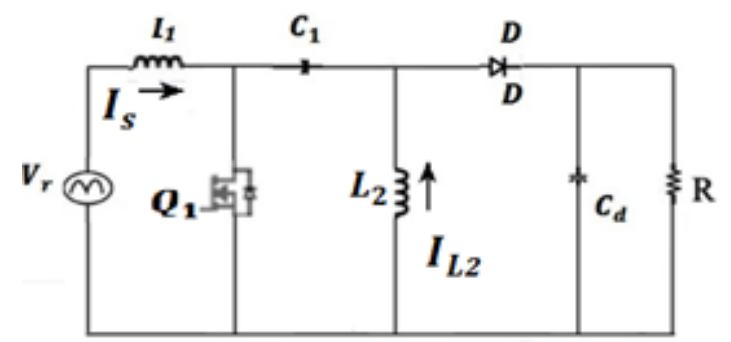

Fig. 5. Mode2

The current, voltages profile for SEPIC components are shown in figure. 6

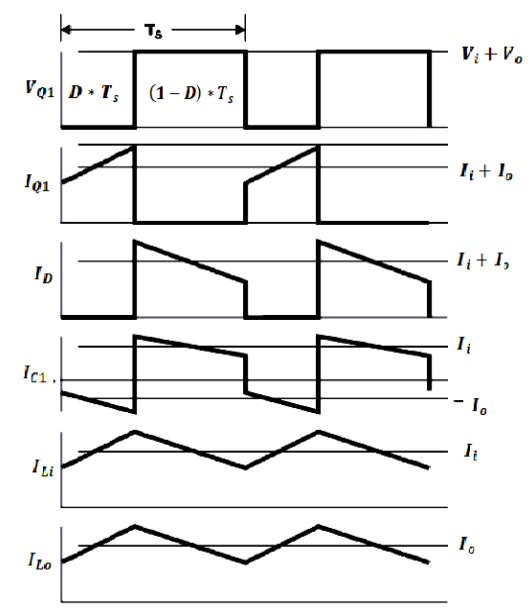

Fig. 6. Waveform for Components 


\section{Converter Design}

The induction motor drive mechanism has been suggested by the use of DCM-based SEPIC Converter.

The input voltage is specified as,

$$
\mathrm{V}_{\mathrm{in}}=\frac{2 \sqrt{2} \mathrm{~V}_{\mathrm{S}}}{\pi}
$$

Boost inductor is expressed in [7] as,

$$
\begin{gathered}
\mathrm{L}_{1}=\frac{D \mathrm{~V}_{\text {in }}}{\left\{\mathrm{f}_{\mathrm{s}}\left(\Delta \mathrm{i}_{\mathrm{Li}}\right)\right\}} \\
\mathrm{L}_{2}=\frac{(1-\mathrm{D}) \mathrm{V}_{\mathrm{dc}}}{\left\{\mathrm{f}_{\mathrm{s}}\left(\Delta \mathrm{i}_{\mathrm{Lo}}\right)\right\}}
\end{gathered}
$$

The intermediate capacitor $C_{1}$ is given by [7]

$$
\mathrm{C}_{1}=\frac{\mathrm{DV} \mathrm{V}_{\mathrm{dc}}}{\left\{\mathrm{Rf}_{\mathrm{s}}\left(\Delta \mathrm{V}_{\mathrm{C} 1}\right)\right\}}
$$

Output filter capacitor for converter

$$
\mathrm{C}_{\mathrm{d}}=\frac{\mathrm{I}_{\mathrm{dc}}}{\left\{2 \omega\left(\Delta \mathrm{V}_{\mathrm{dc}}\right)\right\}}
$$

Parameter assortment for conniving SEPIC converter are expressed at table I

Table 1 Converter parameters

\begin{tabular}{|c|c|c|}
\hline Sr. No. & Parameter & Value \\
\hline 1 & $\mathrm{~V}_{\mathrm{s}}$ & $230 \mathrm{~V}$ \\
\hline 2 & $\mathrm{~L}_{1}$ & $3.8 \mathrm{mH}$ \\
\hline 3 & $\mathrm{~L}_{2}$ & $5.44 \mathrm{mH}$ \\
\hline 4 & $\mathrm{C}_{1}$ & $1.39 \mu \mathrm{F}$ \\
\hline 5 & $\mathrm{C}_{\mathrm{d}}$ & $732 \mathrm{nF}$ \\
\hline 6 & $\mathrm{f}_{\mathrm{s}}$ & $50 \mathrm{kHz}$ \\
\hline
\end{tabular}

Whereas,

$$
\begin{aligned}
& \mathrm{V}_{\mathrm{s}} \text { - Voltage Source } \\
& \mathrm{L}_{1} \text { - First Inductor } \\
& \mathrm{L}_{2} \text { - Second Inductor }
\end{aligned}
$$

$\mathrm{C}_{1}$ - First Capacitor

$\mathrm{C}_{\mathrm{d}}$ - Second Capacitor

$\mathrm{f}_{\mathrm{s}}$ - Switching Frequency
III. Control for Proposed Scheme

Converter with motor has deliberated for drive scheme and control design for converter comprises of subsequent blocks.

\section{A. PWM Generator}

Output starting from $\mathrm{PI}$ is fed to PWM generator consequently that yields stable frequency PWM signal and variable duty ratio. Output heading since PI controller is equated with sawtooth signal furthermore PWM is generated.

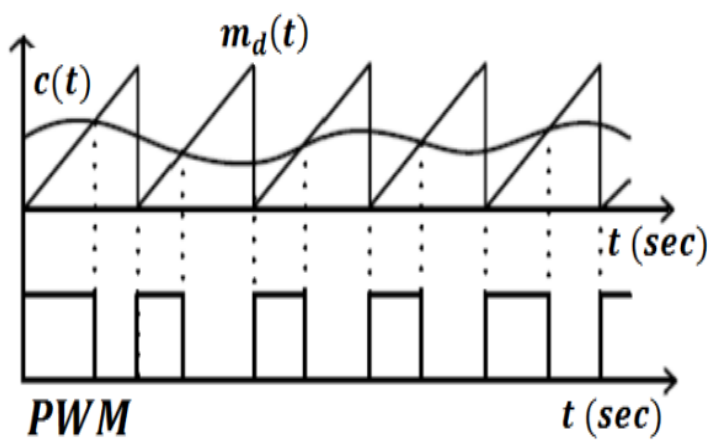

Fig. 7. Pulses

\section{B . Control for Front End SEPIC Converter}

Generally, two control designs are adopted at PFC converters that are Voltage follower and current multiplier approaches and process in DCM as well as CCM are decisive by such control approaches respectively. The Voltage follower method is employed in planned work so that dc voltage $\mathrm{V}_{\mathrm{dc}} *$ is preferred as reference and equated with $V_{d c}$ to cause error voltage.

Error signal starting from $\mathrm{V}_{\mathrm{dc}} *$ and $\mathrm{V}_{\mathrm{dc}}$ is fed to PI to produce outcome relating to error signal.

The slip(error) voltage by any instant [8],

$$
\mathrm{V}_{\mathrm{e}}(\mathrm{k})=\mathrm{V}_{\mathrm{dc}} *(\mathrm{k})-\mathrm{V}_{\mathrm{dc}}(\mathrm{k})
$$

Error voltage is supplied to PI for creating controlled voltage across output.

The outcome for PI controller $\mathrm{V}_{\mathrm{c}}(\mathrm{k})$

$$
\mathrm{V}_{\mathrm{c}}(\mathrm{k})=\mathrm{K}_{\mathrm{i}} \mathrm{V}_{\mathrm{e}}(\mathrm{k})+\mathrm{K}_{\mathrm{p}}\left(\mathrm{V}_{\mathrm{e}}(\mathrm{k})-\mathrm{V}_{\mathrm{e}}(\mathrm{k}-1)\right)+\mathrm{V}_{\mathrm{c}}(\mathrm{k}-1)
$$

Where,

$\mathrm{K}_{\mathrm{p}}$ and $\mathrm{K}_{\mathrm{i}}$ are steady for proportional gain and integral gain correspondingly.

Saw-tooth signal is matched with controller upshot to create pulses for switching a converter switch.

\section{Simulations and Result}

The scheme is investigated at MATLAB in order to ensure behavior for open loop as well as closed loop. 
Simulink model of SEPIC converter is revealed in Fig.8

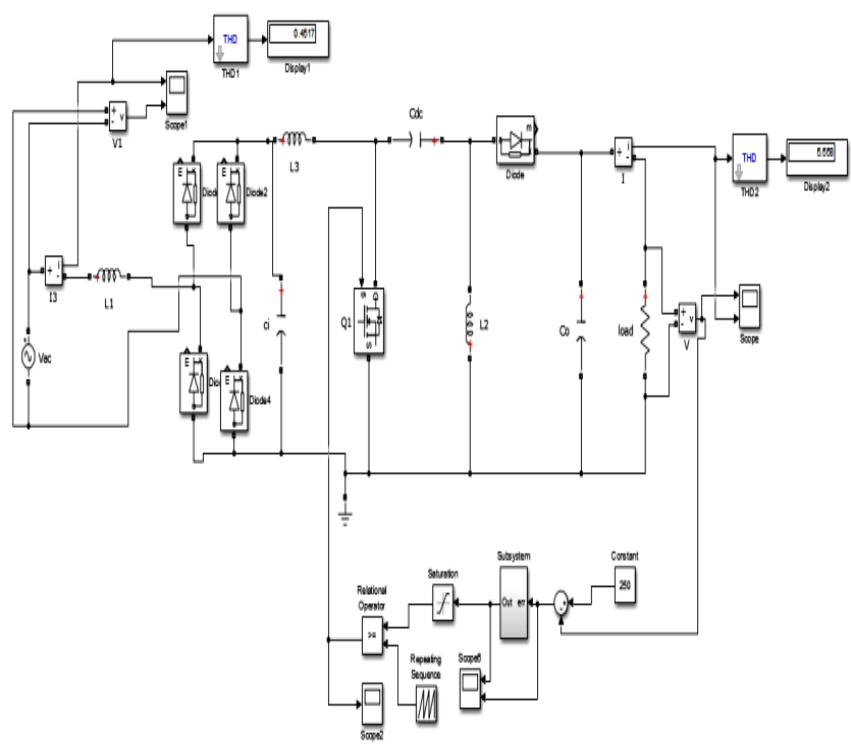

Fig. 8. Simulink Model for SEPIC

The voltage and current waveform for open loop SEPIC converter is depicted as in Fig. 9(a) along with Fig.9(b).

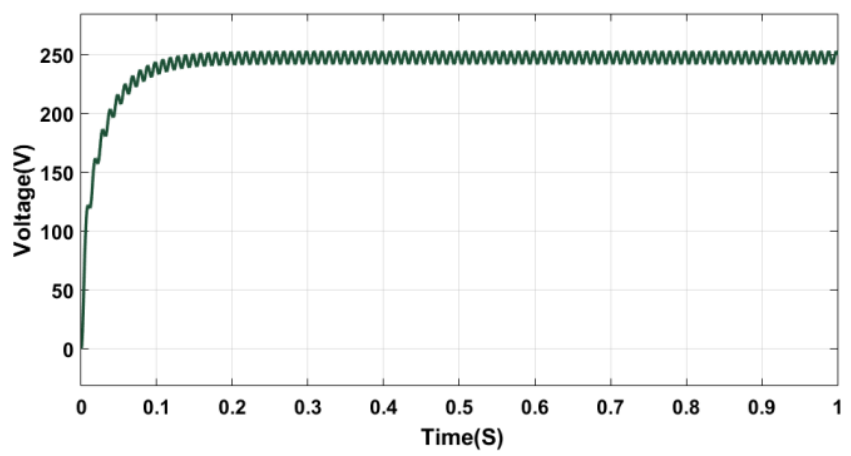

Fig. 9 (a)Voltage for Open Loop

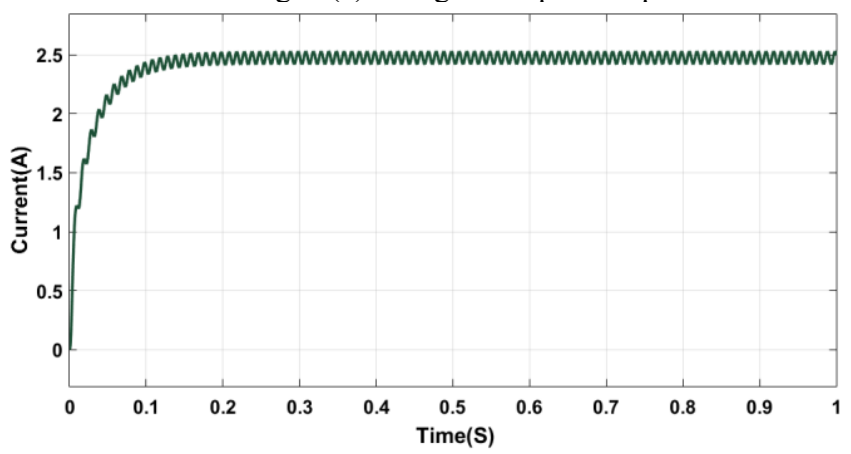

Fig.9 (b). Current for Open Loop

The voltage along with current waveform for closed loop SEPIC is represented by Fig.10(a) with Fig.10(b).And error voltage is regulated with PI that offers a feedback control to advances operation for SEPIC converter.

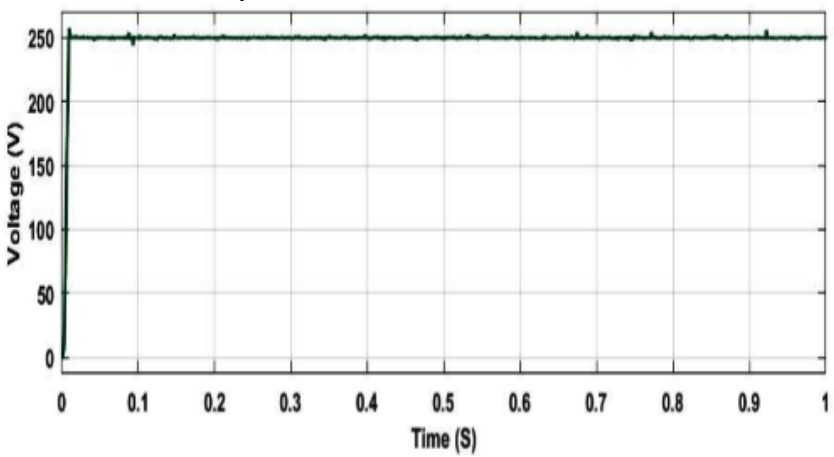

Fig.10(a)Voltage for Closed Loop

During closed loop operation both the waveform of voltage and currents achieves the stability after 0.015 seconds for $251 \mathrm{~V}$ and 2.51 A respectively.

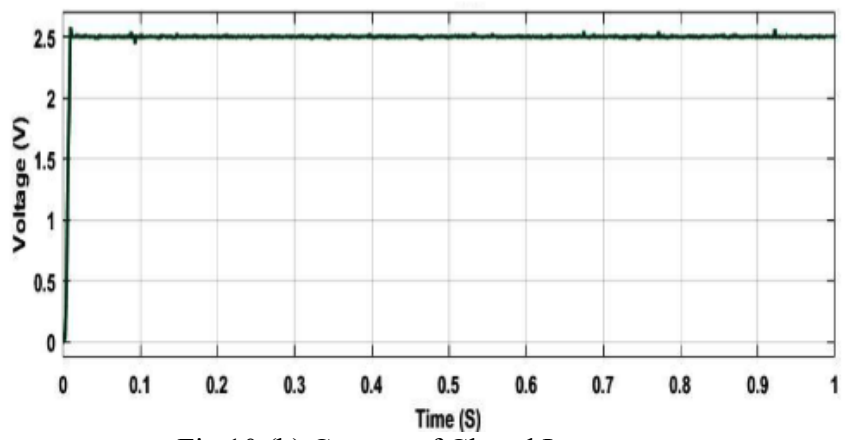

Fig.10 (b) Current of Closed Loop

- Closed loop process has accuracy and reliability for preferred outcomes for system results. This control operation is achieved by utilizing voltage follower approach along with PI control.

Speed is restricted with such control by utilizing PID control. The waveform for speed is revealed in Fig.11.consequently motor gained constant speed of about $1470 \mathrm{rpm}$ at $0.4 \mathrm{sec}$ depicted in Fig. 11 below.

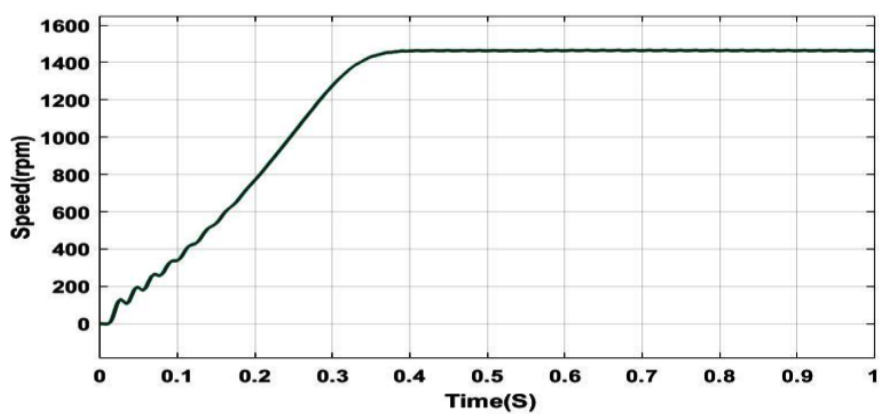

Fig.11. Speed vs time graph

Fig.12 demonstrates profile for electromagnetic torque. primarily the motor coerces more torque as having privileged inertia while starting. Whenever constant speed is achieved by motor, torque necessity is also abridged relating to speed. 


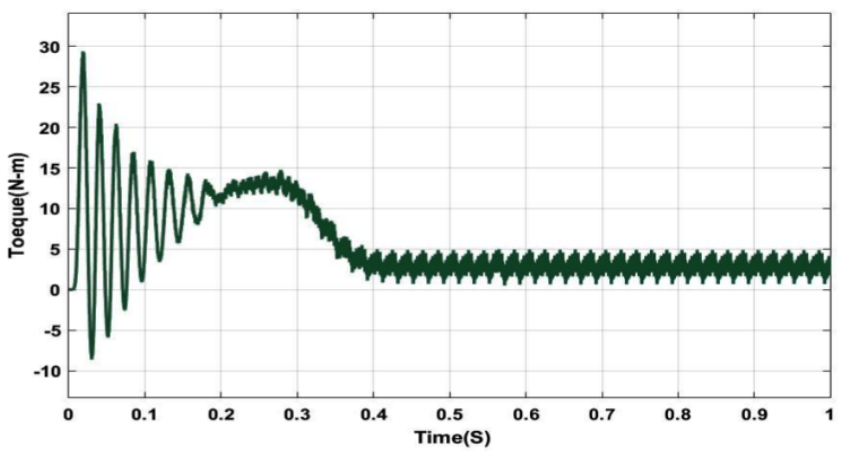

Fig.12. Torque vs time graph

The waveform for stator current is expressed in Fig.13. The preliminary current for induction motor is almost 5-7 times of rated current. During starting motor draws more magnetizing current nearly line of rated current and after 0.4 sec motor current becomes constant.

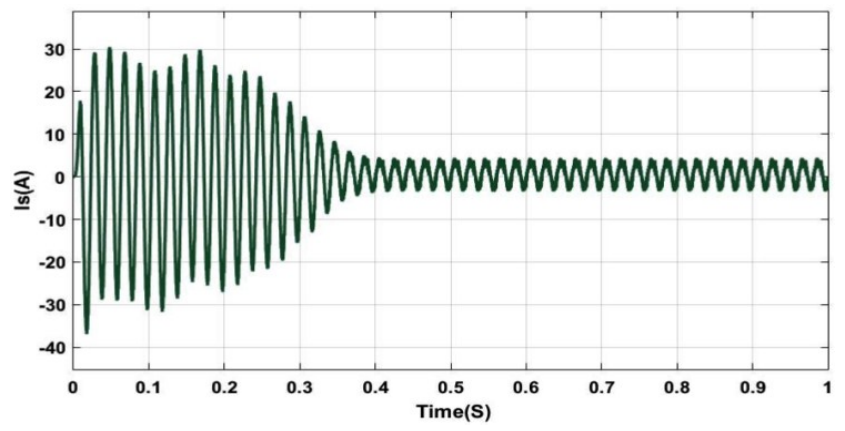

Fig.13. Stator Current vs time graph

The summarized result analysis for proposed scheme is revealed at table. II

Table 2 Result of Converter

\begin{tabular}{|c|c|}
\hline Parameters & Value \\
\hline Settling Time & $0.016 \mathrm{~S}$ \\
\hline Voltage & $251.1 \mathrm{~V}$ \\
\hline Current & $2.511 \mathrm{~A}$ \\
\hline THD & $1.835 \%$ \\
\hline PF & 0.95 \\
\hline Efficiency (\%) & $82.63 \%$ \\
\hline
\end{tabular}

\section{CONCLUSION}

Novel scheme for PFC SEPIC converter supplied induction motor drive has anticipated as well as simulated in MATLAB, for enhancement of power quality along with inferior THD and voltage regulation through diverse speed control. The closed loop operation for SEPIC provides a reduced THD of $1.835 \%$ and efficiency of $82.63 \%$ along with augmented power factor of 0.95. Converter is premeditated to execute in DCM working with voltage

follower methodology to systematize voltage. Additionally, it is imperative to conceal that projected converter offers considerable PQ advancement irrespective for load and supply voltage variations. By utilizing this converter, VSI worked at lesser frequency with condensed losses in switching.

\section{References}

[1] A. Stepanov, "Galvanically isolated MPPT DC/DC converter for PV system tied to DC grid," Electronic and Electrical Engineering (AIEEE in 2015 IEEE 3rd Workshop on Advances inInformation,), 2015, pp. 1-4.)

[2] Swati Narula,et.al., "Bridgeless Single-Ended Primary Inductance Converter with Improved Power Quality for Welding Power Supplies"978-1-4799-6046-0/14/\$31.00 (C)2014 IEEE

[3] Falcondes J, Angelo C. Lourenço,João C. Pelicer Junior2 et.al., "18-Pulse autotransformer rectifier unit using SEPIC converters for regulated dc-bus and high frequency isolation", 978-1-4799-8779-5/15/\$31.00 (C) 2015 IEEE

[4] Dr. Jayapraksh P, Nirmal Mukundan C. M., , "Solar PV fed Cascaded H-Bridge Multilevel Inverterand SIMOSEPIC based MPPT controller for 3-PhaseGrid Connected System with Power QualityImprovement"1820,2017978-1-5386-3236-9/17/\$31.00@ National Power Electronics Conference (NPEC) College of Engineering Pune, India,Dec IEEE.2017

[5] Nirmal Mukundan,et.al ."Isolated SEPIC Converter fed Trinary Hybrid Cascaded H-bridge Multilevel Inverter for Solar PV System" IEEE Region 10 Symposium (TENSYMP), 978-1-5090-6255-3/17/\$31.00 $\quad$ (C)2017 IEEE

[6] Yie-Tone Chen, Sheng-Zhi Mo "A Bridgeless ActiveClamp Power Factor Correction Isolated SEPIC Converter with Mixed DCM/CCM Operation

[7] Saurabh Shukla, Sanjeev Singh," Improved Power Quality PMBLDC Motor Drive for Constant Speed Variable Torque Load using Non-Isolated SEPIC Converter ", 2014 Annual IEEE India Conference (INDICON), 978-1-4799-5364-6/14/\$31.00 (C2014 IEEE

[8] Bhim Singh Vashist Bist, et.al "Power Factor Correction in Bridgeless-Luo Converter Fed BLDC Motor Drive", 0093-9994 $\quad$ (c) $2013 \quad$ IEEE DOI 10.1109/TIA.2014.2344502, IEEE Transactions on Industry Applications 